admitted that salmon return to the streams where they were born-and there is much evidence supporting that view-it cannot be admitted that either the temperature of a particular stream or the swift. ness of its current remains constant. It is difficult to understand, therefore, just how these variable factors can guide migrating salmon, not to a specially cold or swift stream, but to a particular stream the one outstanding character of which is that they were born there.

\section{U.S. Zoological Expedition to Far East}

A PARTy of scientific workers from Harvard and Johns Hopkins Universities has set out with the intention of making a survey of the birds and mammals of Siam, Borneo and Sumatra (Science Service, Washington, D.C.). The results should be of special significance, for the programme includes study of the social life of some of the most interesting of the higher monkeys. In the jungles of Siam, the habits of the gibbons will be observed for three or four months by Dr. Carpenter; other members of the expedition will carry out parallel observations in British North Borneo on orang-utans, gibbons and proboscis monkeys; while, later, in the mountains of northern Sumatra, orang-utans will be studied in the national park recently set aside by the Netherlands Government to protect this rapidly disappearing animal. It is expected that the study of the social habits of these creatures may throw light upon the problems of man's social and physical evolution.

\section{Radio-Therapeutic Treatment of Cancer}

THE Ministry of Health has issued an important publication on cancer treatment entitled "Cancer : Memorandum on Provision of Radio-Therapeutic Departments in General Hospitals", by Lieut. Colonel Smallman (Reps. on Pub. Health and Med. Subjects, No. 79. London : H.M. Stationery Office. 9d. net). A principal reason for the preparation of this memorandum is the growing use of radium and X-rays in the treatment of cancer, in substitution for, or in conjunction with, surgery. As a result, hospitals in which cancer patients are treated need to be specially equipped and staffed for this part of their work. The memorandum emphasizes the importance of team work, and that the radiotherapeutic department should be in close touch not only with the surgical department, but also with other departments (gynæcological, pathological, etc.) provided by the hospital of which it should form an integral part. It concludes that a general hospital should contain some three hundred beds if it is to make reasonably full use of radiation treatment facilities. Plans are given for the lay-out of a radiotherapeutic department, the various features of which are explained in the text. The memorandum discusses how those hospitals which cannot provide full cancer treatment facilities can be enabled to make use of other hospitals in which full facilities exist. Appendixes contain the recommendations of the British X-Ray and Radium Protection Committee and of the Radium Commission on the care and custody of radium.

\section{Physics at Harvard}

THE volume of "Contributions" from the Physical Laboratories of Harvard University for 1935 is again of quarto form and consists of reprints without change of pagination, of fifty-seven memoirs by members of the staff, fellows and students which have appeared in scientific periodicals such as the Physical Review, the Proceedings of the Americar Academy, the Review of Scientific Instruments, during 1935 and the first two months of 1936. The quarto form allows the inclusion of the large double column pages of Indus. trial and Engineering Chemistry, but gives very wide margins to the single column pages of the Proceedings of the Academy. Work on the physical properties of materials at high hydrostatic pressure accounts for seven or eight of the memoirs and special interest is attached to Prof. P. W. Bridgman's method of securing measurements at 50,000 atmospheres pressure in steel vessels which normally rupture at 20,000 atmospheres. Atomic physics accounts for about a dozen memoirs, of which that on the quantum theory of valence by Prof. Van Vleck and Dr. Sherman, a fellow of the National Research Council, reprinted from Reviews of Modern Physics, may be mentioned. The whole volume bears evidence to the active part Harvard is taking in the advance of knowledge.

\section{Field Work of the Smithsonian Institution in 1936}

THE preliminary survey of recent field work of the Smithsonian Institution ("Explorations and Field. Work of the Smithsonian Institution in 1936." Washington, D.C., 1937 ; pp. 100) covers nineteen investigations, beginning with Dr. G. C. Abbot's "Exploring Solar Power Possibilities" and including research in geology, palæontology, zoology, botany and anthropology, the last-named predominating with seven investigations, mostly archæological. Of these last, Dr. Hrdlička's explorations of sites on Kodiak Island, Alaska, and the Aleutian Islands have attracted no little attention, not only on account of the exceptionally large number of antiquities brought back by this year's expedition, but also by the collection of mummified human remains from Kagamil. Dr. Henry B. Collins, jun., by his excavs. tions at Bering Strait, has succeeded in determining beyond question the place of the Thule culture in the cultural succession at this gate of entry of man into the American continent - an important contribution to the Eskimo problem--and also has arrived at the conclusion that there is little hope of discovering any trace here of the passage of early man prior to the Eskimo, owing to physiographic changes. Further investigations by Dr. Frank H. Roberts, jun., on sites of the Folsom culture in Colorado and on a new site in Iowa discovered in 1935, the easternmost occurrence noted of the true Folsom stone point, have yielded new data bearing on the occurrence of this early type of the American stone age. It is now established that Folsom man was contemporary with the extinct camel, and also that he lived before, as well as at the same time as, the thick growth of vegetation which preceded the present condition of 